\title{
A Study of Fetal Middle Cerebral Artery Peak Systolic Velocity to Diagnose Fetal Anemia in Rural Obstetric Population
}

\author{
Sushil Kachewar, Sidappa G Gandage, Hemant J Pawar
}

\begin{abstract}
Globally, fetal middle cerebral artery peak systolic velocity (MCA-PSV) is used for noninvasive diagnosis of fetal anemia. Although, incidence of anemia is common in rural setup, scientific studies describing utilization of this modality are lacking. This study throws light on how the use of fetal MCAPSV to diagnose fetal anemia can help in the decision-making process even in a rural setup.
\end{abstract}

Context: Fetal anemia can be adequately tackled only if it is diagnosed on time. Fetal MCA-PSV has the potential to reliably predict fetal anemia. Scientific studies across the globe are testimony to this fact. As such studies from rural setups are lacking, this study was initiated.

Aims: A study of fetal middle cerebral artery peak systolic velocity to diagnose fetal anemia in rural obstetric population.

Settings and design: The study was conducted in the ultrasound section of a rural medical college. Clearance from institutional ethical and research committee was obtained. Written informed consent was obtained from the pregnant mother. A prospective observational study was conducted over the last 12 months.

Materials and methods: Fetal MCA-PSV was measured in 26 pregnant women referred for ultrasound due to clinical suspicion of fetomaternal abnormality. Middle cerebral artery peak systolic velocity was measured by a single experienced radiologist on color Doppler ultrasound machine.

Statistical analysis used: The observations were entered in Microsoft Excel sheet, and statistical analysis was done by comparing with internationally accepted values at that gestational age. Karl Pearson's correlation coefficient was used to study the relation between fetal MCA-PSV and gestational age. Standard t-test was used to study the significance of difference.

Results: There was a steady increase in MCA-PSV with rising gestational age suggestive of positive correlation between them. When compared with internationally accepted values, significantly raised fetal MCA-PSV values were seen in six patients. These patients were followed up and the cause of fetal anemia in each was identified.

Conclusion: Fetal MCA-PSV can be successfully used to evaluate for anemia in fetuses in a rural setup provided correct methods are followed. An attempt to measure fetal MCA-PSV in face of every fetomaternal adversity is recommended so that none of the cases of fetal anemia go undiagnosed.

Keywords: Fetal anemia, Middle cerebral artery peak systolic velocity, Doppler.

Date of Received: 09-07-13

Date of Acceptance: 07-09-13

Date of Publication: September 2013
Key messages: Proper knowledge and routine measurement of fetal MCA-PSV value can be a life saving noninvasive practice to diagnose fetal anemia in a rural setup.

How to cite this article: Kachewar S, Gandage SG, Pawar HJ . A Study of Fetal Middle Cerebral Artery Peak Systolic Velocity to Diagnose Fetal Anemia in R ural O bstetric Population. Int J Infertility Fetal Med 2013;4(3):83-87.

\section{Source of support: Nil}

Conflict of interest: None

\section{INTRODUCTION}

The exact incidence of fetal anemia is unknown as many cases go unsuspected, unreported or undiagnosed. It is therefore possible that fetal anemia is one of the important causes of intrauterine and perinatal mortality and morbidity. Hence, it will be a blessing in disguise if fetal anemia can be suspected, suggested or diagnosed by non-invasive testing, especially in a rural setup.

$\mathrm{N}$ ot very long ago, amniocentesis ${ }^{1}$ made liquor available for spectrophotometry to assess for bilirubin-a product of hemolysis was the only method. Later the procedure of cordocentesis ${ }^{2}$ made blood available for hemoglobin assessment. As both of these methods were invasive, a noninvasive method to determine fetal anemia was eagerly awaited.

Doppler ultrasound demonstration of elevated fetal middle cerebral artery peak systolic velocities (M CA -PSV) in anemic fetuses filled this void. ${ }^{3,4}$ A s fetal M CA -PSV can rise in a variety of causes leading to fetal anemia, we wanted to evaluate how far this noninvasive test would help us in suggesting a diagnosis of fetal anemia in a rural setup, where many times the cause of intrauterine and perinatal deaths remain unknown.

\section{MATERIALS AND METHODS}

A total of 26 pregnant women with one or the other fetomaternal problems were included in this study after their informed written consent. Institutional ethical and research committee clearance was also obtained. The site of study was the ultrasound section in radiodiagnosis department of this institute. 


\section{INCLUSION CRITERIA}

Maternal indications- primigravida with one or more of following:

Severe anemia, hypertension, diabetes, bleeding per vaginum, consanguineous marriage, family history of hemoglobinopathy, medical and surgical condition complicating pregnancy.

Fetal indications-growth retardation, abnormal free fluid in body cavities, structural abnormality.

Other indications- cord around neck, uterine structural abnormality, anhydramnios, polyhydramnios and abnormal ities of placenta or cord.

\section{EXCLUSION CRITERIA}

Fetus with excess activity, nonconsenting mothers and patients who could not cooperate due to their severe discomfort.

A n experienced sonologist recorded fetal M CA-PSV on Siemens $\mathrm{G} 60$ Doppler ultrasound machine. The examination was performed on supine patient using a $3.5 \mathrm{M} \mathrm{Hz}$ curvilinear transducer to achieve a transverse section of fetal head demonstrating biparietal diameter. Fetal M CA arising from the internal carotid arteries was localized using color flow and sampled at 0 o angle using pulse Doppler. When satisfactory consistent MCA velocity waveforms were obtained, the image was set at freeze option and using the cal iper function, the peak of systolic velocity was measured. Each study took roughly 5 to 15 minutes.

The values of MCA-PSV measured in this study were tabulated in M icrosoft Excel 2007 spreadsheet. The value of each observation was compared to the cut-off value for diagnosing fetal anemia for that gestational age as published in literature ${ }^{3}$ and provisional diagnosis of fetal anemia was put forth when it was significantly elevated. The outcome of these pregnancies was followed and tabulated (Table 1).

\section{RESULTS}

The observed MCA-PSV values were compared with standard published values ${ }^{3}$ to label the fetus as anemic and the follow-up of these pregnancies indicated that out of 26 patients in this study, elevated MCA-PSV values were recorded in six fetuses that were then labelled as anemic.

Figure 1 scatter diagram depicting relationship between fetal MCA-PSV and gestational age. With advancing gestational age, value of M CA-PSV also rises indicating a positive correlation between the two as shown by the solid green line.

\begin{tabular}{|c|c|c|c|c|c|}
\hline $\begin{array}{l}\text { Gestational } \\
\text { age (weeks) }\end{array}$ & $\begin{array}{l}\text { Observed } \\
\text { MCA-PSV } \\
\text { value } \mathrm{cm} / \mathrm{s}\end{array}$ & $\begin{array}{c}\text { Cut-off } \\
\text { value }^{3} \text { of } \\
\text { MCA-PSV }\end{array}$ & $\begin{array}{c}\text { Fetal } \\
\text { anemia }\end{array}$ & $\begin{array}{l}\text { Relevant maternal } \\
\text { history and findings }\end{array}$ & $\begin{array}{l}\text { Final diagnosis anc } \\
\text { follow-up }\end{array}$ \\
\hline 15 & 32 & 30.3 & Present & Consanguinity & Thalassemia \\
\hline 16 & - & 31.7 & - & - & ........ \\
\hline 17 & 28 & 33.2 & Absent & Diabetes & Normal fetus \\
\hline 18 & 28.3 & 34.8 & Absent & Sickle cell disease & Normal fetus \\
\hline 19 & - & 36.5 & - & - & ........ \\
\hline 20 & 22 & 38.2 & Absent & Diabetes & Normal fetus \\
\hline 21 & 22 & 40.0 & Absent & Hepatitis & Normal fetus \\
\hline 22 & 46.3 & 41.9 & Present & $\begin{array}{l}\text { Hypertensive } \\
\text { Mother }\end{array}$ & $\begin{array}{l}\text { Materno-fetal } \\
\text { Insufficiency-IUD }\end{array}$ \\
\hline 23 & 25.6 & 43.9 & Absent & Bleeding $\mathrm{P} / \mathrm{V}$ & Normal fetus \\
\hline 24 & 31.1 & 46.0 & Absent & Absent right fetal kidney & Normal fetus \\
\hline 25 & 28.5 & 48.2 & Absent & Severe maternal anemia & Normal fetus \\
\hline 26 & 51.7 & 50.4 & Present & Bleeding $\mathrm{P} / \mathrm{V}$ & $\begin{array}{l}\text { IUD due to large } \\
\text { retroplacental } \\
\text { hematoma }\end{array}$ \\
\hline 27 & 38.8 & 52.8 & Absent & Bicornuate uterus & Normal fetus \\
\hline 28 & 56.0 & 55.4 & Present & $\begin{array}{l}\text { Maternal parvovirus } \\
\text { B19 infection }\end{array}$ & $\begin{array}{l}\text { Parvovirus B } 19 \\
\text { infection, IUD }\end{array}$ \\
\hline 29 & 59.8 & 58.0 & Present & Anhydramnios & P reterm delivery \\
\hline 30 & - & 60.7 & - & - & - \\
\hline 31 & 66.9 & 63.6 & Present & $\begin{array}{l}\text { Hypertensive } \\
\text { Mother }\end{array}$ & $\begin{array}{l}\text { Materno-fetal } \\
\text { Insufficiency }\end{array}$ \\
\hline 32 & 43.4 & 66.6 & Absent & Polyhydramnios & Normal fetus \\
\hline 33 & 49.1 & 69.8 & Absent & IUGR & Normal fetus \\
\hline 34 & - & 73.1 & - & - & - \\
\hline 35 & - & 76.6 & - & - & - \\
\hline 36 & 51.3 & 80.2 & Absent & Cord around neck & Normal fetus \\
\hline 37 & 49.7 & 84.0 & Absent & Diabetes & Normal fetus \\
\hline 38 & - & 88.0 & - & - & - \\
\hline 39 & 61.8 & 92.2 & Absent & Hypertension & Normal fetus \\
\hline 40 & 62.3 & 96.6 & Absent & Severe maternal anemia & Normal fetus \\
\hline
\end{tabular}


O ut of the six fetuses that were labeled as anemic due to their abnormally raised M CA-PSV, follow-up demonstrated thalassemia in one, materno-fetal insufficiency in two, anhydramnios in one, parvovirus B 19 infection in one and large retroplacental hematoma in one.

Thus, the presence of fetal anemia could be accurately predicted in all of them.

\section{DISCUSSION}

Fetal anemias can occur due to red blood cell alloimmunization, homozygous alpha-thalassemia, massive fetomaternal hemorrhage, parvovirus B 19 infection and twin-twin transfusion syndrome. ${ }^{3-6}$

Defective synthesis of alpha-globin chains results in al pha-thal assemia and it can be confirmed by DNA analysis of the amniotic fluid. Fetal anemia suggested by elevated M CA -PSV is confirmed by cordocentesis anemia. ${ }^{6}$

M echanisms ${ }^{6}$ leading to raised MCA-PSV in fetal anemia are as follows:

1. Reduced blood viscosity due to lowered hematocrit causing increase in blood flow velocities.

2. Increase in cardiac output has to compensate for reduced oxygen carrying capacity of the blood due to fetal anemia.

Increased M CA -PSV in fetal anemia is a widely accepted choice of investigation rather than other parameters like liver length and spleen perimeter in homozygous alphathalassemia $1 .{ }^{6}$ A mniotic fluid DNA analysis is time consuming where as measuring M CA -PSV enables a faster diagnosis of fetal anemia and enables to properly time cordocentesis and intrauterine transfusion. Successful outcome has been reported after intrauterine transfusion, though it is not a standard treatment. 6,7

Elevated MCA-PSV sheds light on the impending danger of fetal hydrops well in advance to take adequate corrective steps. $^{6}$

Figure 2 shows elevated MCA-PSV in a fetus at 15 weeks of gestation. There was history of consanguinity in the family. After delivery, the fetus was confirmed to have al pha-thalassemia, which is inherited as an autosomal recessive entity and has the potential to manifest as anemia in fetus from first trimester onwards. ${ }^{5} \mathrm{~A}$ frica, south-east $\mathrm{A}$ sia and the middle-East are its homelands. Recurrence is seen in one-fourth of the pregnancies.

Figure 3 shows elevated M CA-PSV in a fetus at 22 weeks of gestation with severe materno-fetal insufficiency in a severely hypertensive mother.

Figure 4 shows elevated MCA-PSV in a fetus at 26 weeks of gestation with IUD due to large retroplacental hematoma. Fetomaternal hemorrhage $(\mathrm{FM} \mathrm{H})$ is usual ly seen in patients who notice decreased or absent fetal movements

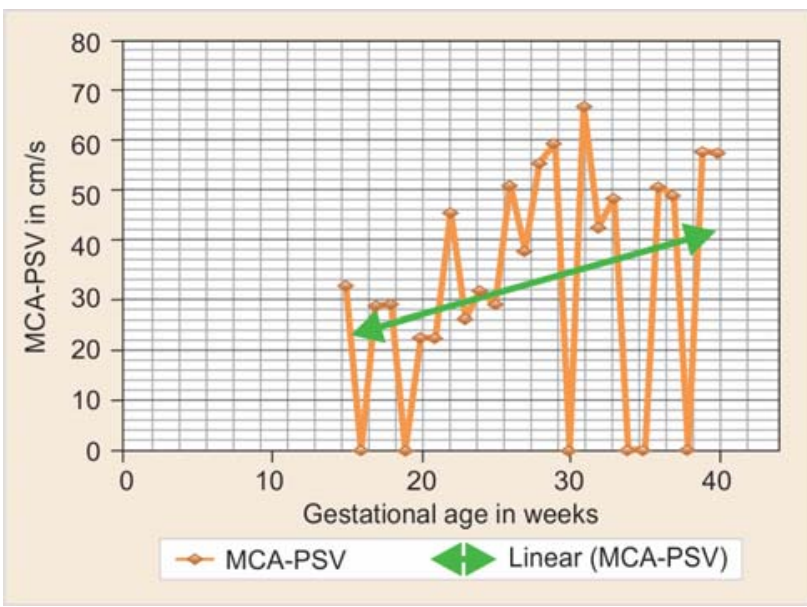

Fig. 1: Scatter diagram depicting relationship between fetal MCA-PSV and gestational age

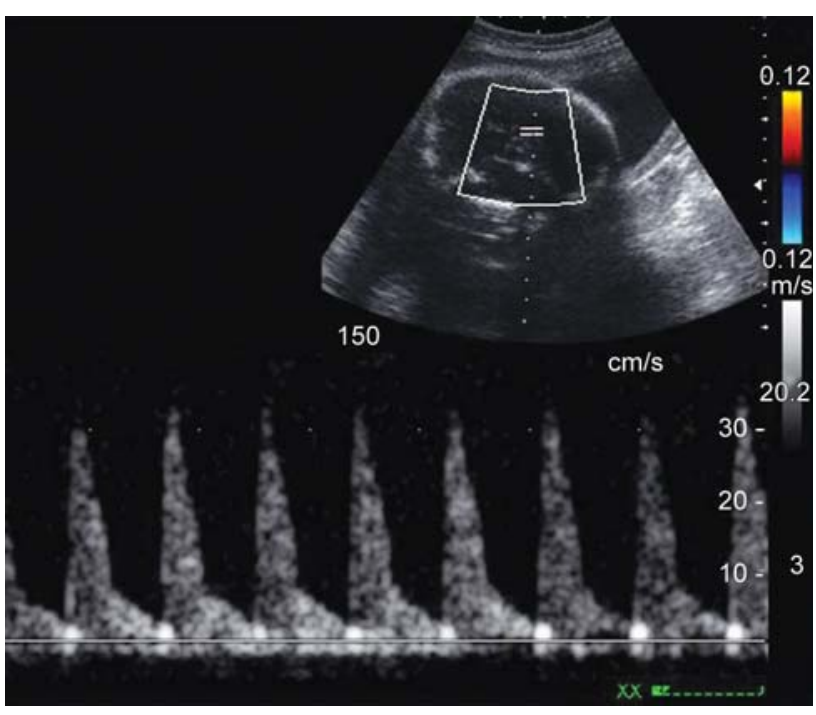

Fig. 2: Elevated MCA-PSV in a fetus at 15 weeks of gestation with thalassemia

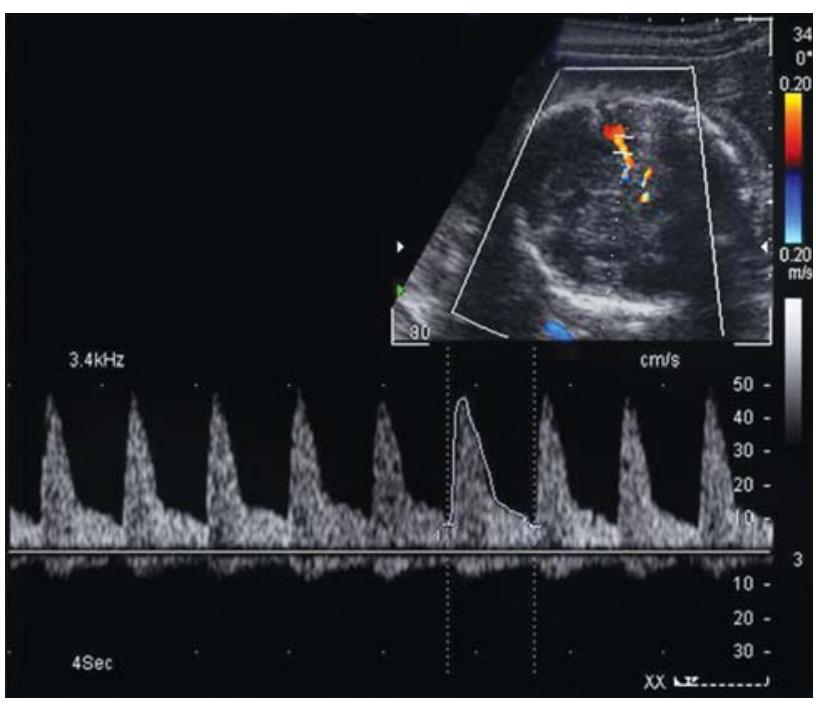

Fig. 3: Elevated MCA-PSV in a fetus at 22 weeks of gestation with severe materno-fetal insufficiency in a severely hypertensive mother 
and leads to elevated MCA-PSV. ${ }^{8}$ A cute hypovolemia leading to hypoxemia is the underlying mechanism of fetal damage. When massive FMH can cause fetal anemia, hydrops and even death.

M orbid postnatal conditions, like damage to central nervous system as well as respiratory distress, are al so possible thereby increasing perinatal mortality range up to $50 \%{ }^{9}$

Figure 5 shows elevated MCA-PSV in a fetus at 28 weeks of gestation with fetal parvovirus B 19 infection which can cause fetal anemia, hydrops and even intrauterine deaths. ${ }^{10}$ Demonstration of viral DNA in amniotic fluid or blood by means of positive polymerase chain reaction (PCR) indicated an infected fetus whereas positive serum PCR and presence of $\mathrm{IgM}$ antibodies in mother indicate maternal infection. ${ }^{11}$

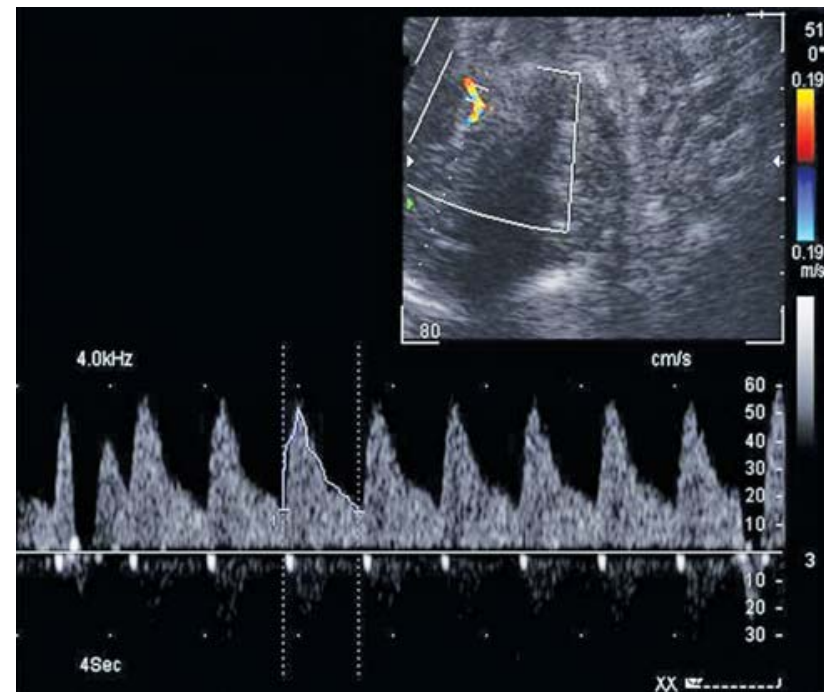

Fig. 4: Elevated MCA-PSV in a fetus at 26 weeks of gestation with IUD due to large retroplacental hematoma

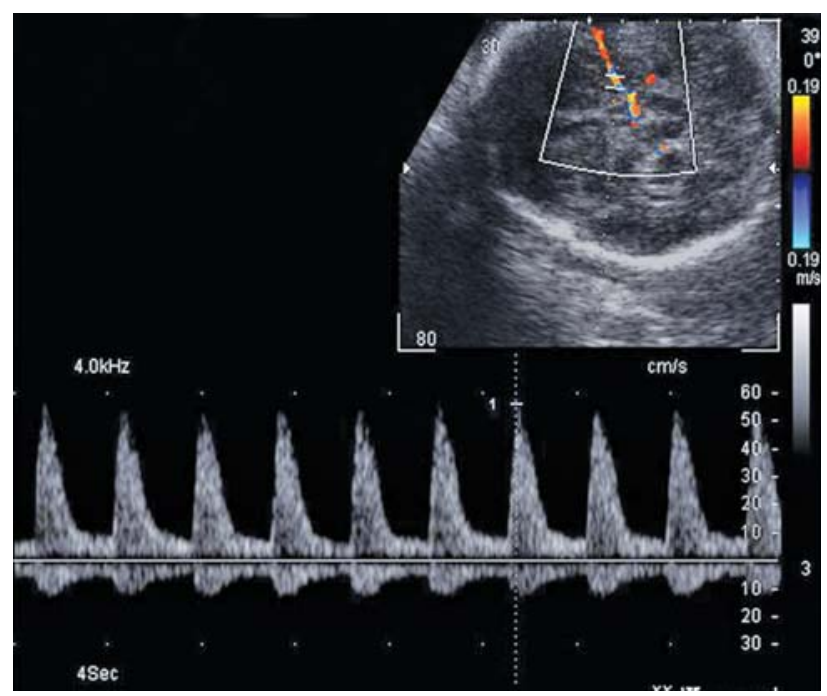

Fig. 5: Elevated MCA-PSV in a fetus at 28 weeks of gestation with fetal parvovirus B19 infection
Elevated M CA-PSV in parvovirus B 19 infected fetuses has high sensitivity and specificity for diagnosing anemic fetus. ${ }^{11}$ Other infective agents, like cytomegalovirus, toxoplasmosis and treponema pall idum too, can infect fetus. However, mild anemia can be caused by all but massive ascites and severe fetal anemia are most common with parvovirus B 19 infection. ${ }^{12}$

Figure 6 shows elevated MCA-PSV in a fetus at 29 weeks of gestation with anhydramnios and preterm delivery. Infant was severely anemic after blood and received exchange transfusions before being discharged in satisfactory condition.

Figure 7 shows elevated M CA-PSV in a fetus at 31 weeks of gestation with severe materno-fetal insufficiency in a severely hypertensive mother.

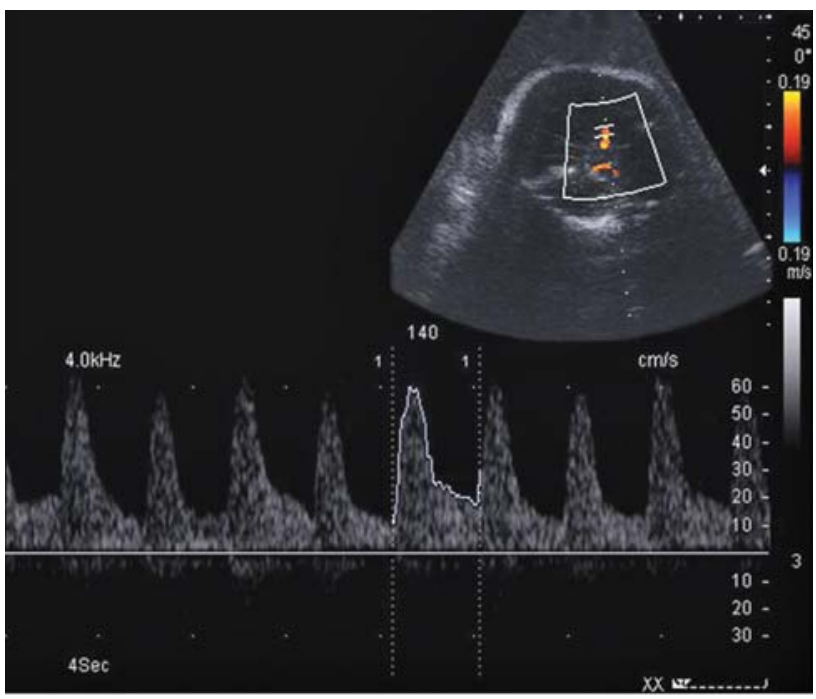

Fig. 6: Elevated MCA-PSV in a fetus at 29 weeks of gestation with anhydramnios and preterm delivery

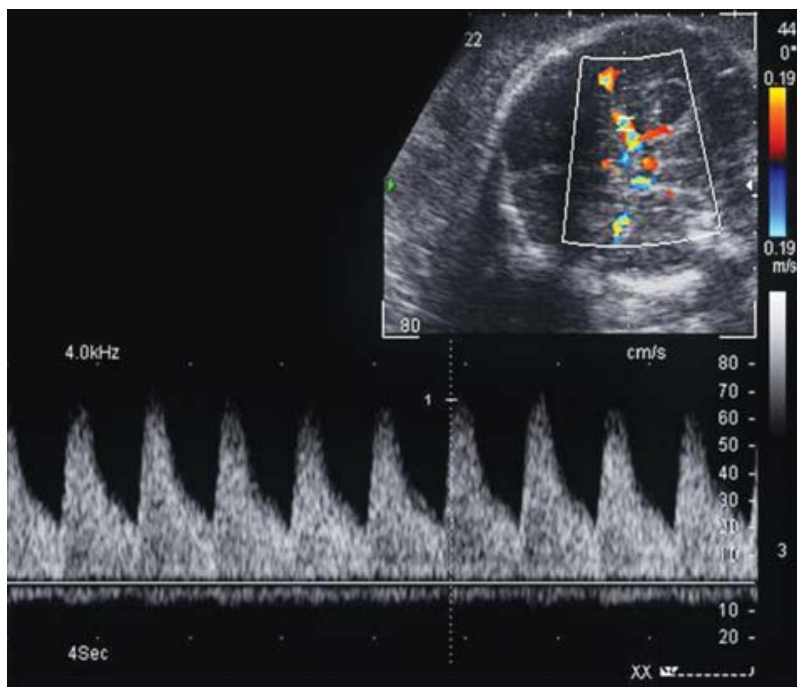

Fig. 7: Elevated MCA-PSV in a fetus at 31 weeks of gestation with severe materno-fetal insufficiency in a severely hypertensive mother 
Thus as shown in figures 2 to 7, abnormally elevated fetal M CA-PSV can noninvasively suggest and even clinch the diagnosis of fetal anemia. The exact quantification and determination of cause needs invasive procedures, like amniocentesis or cordocentesis. On rectifying the anemia, value of MCA-PSV reduces and hence the incidence of invasive procedures, like amniocentesis and cordocentesis, can be reduced. ${ }^{13}$

Our study is the first from this nation to demonstrate successful usage of M CA -PSV in determining fetal anemia in a rural setup.

The strengths of our study are that MCA-PSV was measured by a single experienced observer and the universally accepted method was followed as shown in all figures. But, the small sample size of this study is a limitation. This study needs to be done not only on a large scale but at different locations to validate the efficacy of MCA-PSV in noninvasive diagnosis of fetal anemia.

\section{CONCLUSION}

Fetal anemia can be diagnosed noninvasively by measuring fetal M CA -PSV values. A s this is rapid, reproducible, simple and reliable method and the inter or intraobserver variability is minimal; hence, it can be employed in all patients- rural as well as urban - for successful management of fetal anemia.

\section{REFERENCES}

1. Liley A W. Liquor amnii analysis in the management of pregnancy complicated by rhesus sensitization. A m J Obstet Gynecol 1961;82:1359-1370.

2. Nicolaides KH, Soothill PW, Rodeck CH, Clewell W. Rh disease: intravascular fetal blood transfusion by cordocentesis. Fetal Ther 1986;1:185-192.

3. $M$ ari G, Deter RL, Carpenter RL, Rahman F, Zimmerman R, $M$ oise KJ , etal. N oninvasive diagnosis by Doppler ultrasonography of fetal anemia due to maternal red-cell alloimmunization. Collaborative Group for Doppler Assessment of the Blood V elocity in A nemic Fetuses. N Engl J M ed 2000; 342:9-14.

4. Hernandez-A ndrade E, Scheier M, Dezerega V, Carmo A, $\mathrm{Nicolaides}$ KH. Fetal middle cerebral artery peak systolic velocity in the investigation of non-immune hydrops. Ultrasound O bstet Gynecol 2004;23:442.
5. Lam Y H, Tang M H, LeeCP, TseHY. Cardiac blood flow studies in fetuses with homozygous al pha-thal assemia 1 at 12-13 weeks of gestation. Ultrasound Obstet Gynecol 1999;13:48-51.

6. L eung W C, Oepkes D, Seaward G, Ryan G. Serial sonographic findings of four fetuses with homozygous al pha-thalassemia 1 from 21 weeks onwards. Ultrasound O bstet Gynecol 2002;19: 56-59.

7. Carr S, Rubin L, Dixon D, Star J, Dailey J. Intrauterine therapy for homozygous alpha-thalassemia. Obstet Gynecol 1995;85: 876-879.

8. Sueters $M$, A rabin B, D, Oepkes D. Doppler sonography for predicting fetal anemia caused by massive fetomaternal haemorrhage. Ultrasound Obstet Gynecol 2003;22:186-189.

9. A kanli LF, Cohen-A ddad NE, M alabanan NV, M argono F, K ril ov M A. M assive fetomaternal haemorrhage. A $m$ J Perinatol 1997;14:271-273.

10. Brown T, A nand A, Ritchie LD, Clewley JP, Reid TMS. Intrauterine parvovirus infection associated with hydrops fetalis. L ancet 1984;2:1033-1034.

11. Delle Chiaie L, Buck G, Grab D, Terinde R. Prediction of fetal anemia with Doppler measurement of the middle cerebral artery peak systolic velocity in pregnancies complicated by maternal blood group alloimmunization or parvovirus B 19 infection. UItrasound Obstet Gynecol 2001;18:232-236.

12. Hernandez-A ndrade $E$, Scheier $M$, Dezerega $V$, Carmo A, Nicolaides KH. Fetal middle cerebral artery peak systolic velocity in the investigation of non-immune hydrops. Ultrasound Obstet Gynecol 2004;23:442-445.

13. Stefos T, Cosmi E, D etti L, M ari G. Correction of fetal anemia on the MCA -PSV . Obstet Gynecol 2002;99:211-215.

\section{ABOUT THE AUTHORS}

\section{Sushil Kachewar (Corresponding Author)}

Associate Professor, Department of Radiodiagnosis, Rural M edical College, Loni, M aharashtra, India, e-mail: sushilkachewar@ hotmail.com

\section{Sidappa G Gandage}

Professor and Head, Department of Radiodiagnosis, Rural M edical College, Loni, M aharashtra, India

\section{Hemant J Pawar}

A ssociate Professor, Department of M edical Records and Statistics Rural M edical College, Loni, M aharashtra, India 